\title{
Through a Stereoscopic Viewer: Transient Moments in Remembered Thyme
}

\author{
Cynthia M. Morawski \\ University of Ottawa
}

\begin{abstract}
From the emulsion of images taken yesterday, we develop our engagement in time today-the then that is always changing into now. Weathered shutters close together. Driftwood shifts on rocky sand. Sedges grow among the seashells. Grasses ground a concert band. Seen through the sights of a stereoscopic viewer, the author uses both her word and image to travel through presents in retaken pasts-portals into the practice of her language arts classroom life. The thought of a carousel going round, turns writing into other ways for words to resound. The recollection of sepia on a rooftop at night changes voice into variegations of color and light. It is in these moments of remembered scenes that the author reconsiders what her teaching means.
\end{abstract}

Keywords: writing; photographic inquiry; poetic inquiry; English Language Arts 


\section{Through a Stereoscopic Viewer: Transient Moments in Remembered Thyme}

\section{Prologue}

Memory always appears as an integral element of my teaching narrative whenever I ask myself who I am as an educator of teacher candidates in language/arts. Specific recollections, the ones that Annie Dillard (1982) describes as "no longer unnoticed but now selected out for some meanings, large and unknown" (p. 92), emerge from within me as the shifting of images and sounds found in poetry and art: Plays of words in McGilligott's Pool (Seuss, Dr. 1947); patterns of octagons on a grandmother's garden quilt; and purple paint covering the side of a New England Cape Cod. Alfred Adler, a leading researcher in memory work in narrative, recognizes our recollections as signifiers of how we know and perform in the present (Hestor, 2004; Schneider \& Stone, 1998). That is, what we choose to recall from the past, represents our perceptions and practice in the recurring now. I find myself continually compelled by the need to make sense of my life in language/arts. The parts that specific recollections play in the enactment of my teaching already exist in the pages of academic sites (Morawski, 2008, 2009, 2010; Morawski \& Palulis 2009). The piece that follows adds to these narrations. Placing myself in the path of public scrutiny is never an easy task. Expressing myself via generated poetry and artsinformed means, where "different mediums reveal different interpretations and possibilities" (Butler-Kisber, 2010, p. 9), always adds a definite dimension of vulnerability. However, inspired by Cisneros (2009), who so eloquently and humbly recounts her own poignant moments as a teacher-narrator, even after encountering "a famous writer who went to the Iowa Workshop... and speaks and carries himself as the Emperor of Everything” (p. xx), I venture forth once again to add another layer of insight, a further glimpse into my ever evolving narrative of teaching.

In between a bank of borrowed books and the check-out counter, an oak table stood still for many years. Upon its quarter sawn top sat a collection of vintage cards and their stereoscopic viewers-wooden curiosities from a former time. During each visit to the public library as a child, I was forever drawn to those objects of illusion. They had a way of performing tricks of depth-magic shows for the mind. It didn't matter that I could have easily walked across the street to the movie theatre, or plugged my right ear into a transitor radio. The viewers, stocked with double images of town sites, enchanted my mind with an aesthetic that no other medium could evoke. (C. Morawski, personal communication, undated)

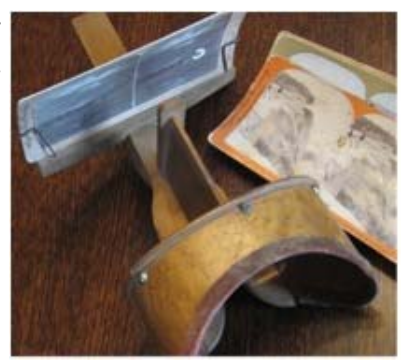

According to Adler (1958), we are both the photographer and the picture, creating our recurring presents from selected moments of archived pasts. That is, from the emulsion of images taken yesterday, we develop our engagement in time today-the then that is always changing into now. In the pre-service curriculum of my own language arts teaching, memories appear in the practices of classroom life. The thought of a carousel going round, turns writing into other ways for words to resound. The recollection of sepia on a rooftop at night changes voice into variegations of color and light. It is in the fragments of experience, Leggo (2007) reminds us, that we find "significance in the moment, in the particular, in the mundane" (p. 194). 


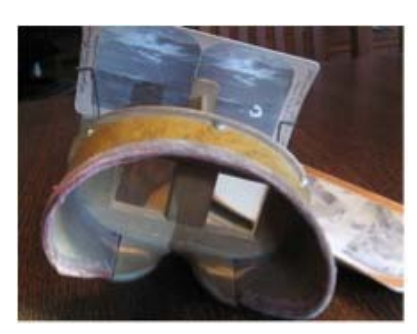

Still lured by the sights of the stereoscopic viewer, I now focus on the present, traveling by train through snapshots in retaken pasts-portals of perception into the practice of my classroom life (Connelly and Clandinin, 2006). The following pages are memories from selected moments that help me make meaning. With my own word and image I look through the lens, while seeing each scene in both past and present tense. I invite you to view, and feel what you think. Now will become then, before your eye can even blink.

A lone train travels into transient scenes of waiting pages.

Bells signal the start of another approaching day.

Outside the coach's window,

images rearrange themselves

into moments remembered last May

Overhead a shelf holds remnants of past routes from current stops.

Station platforms place familiar names on inner walls.

Sitting beside an empty seat,

a camera takes unwritten texts

on a rocky ledge by cedar falls.

Across four beveled edges

Refracting pieces of velum light, She reaches for a box of tincture

To ink away an obsidian night.

Smuggled thoughts travel freely from inside a wrinkled sleeve, An unspoken scene waits inside her self Standing under falling leaves.
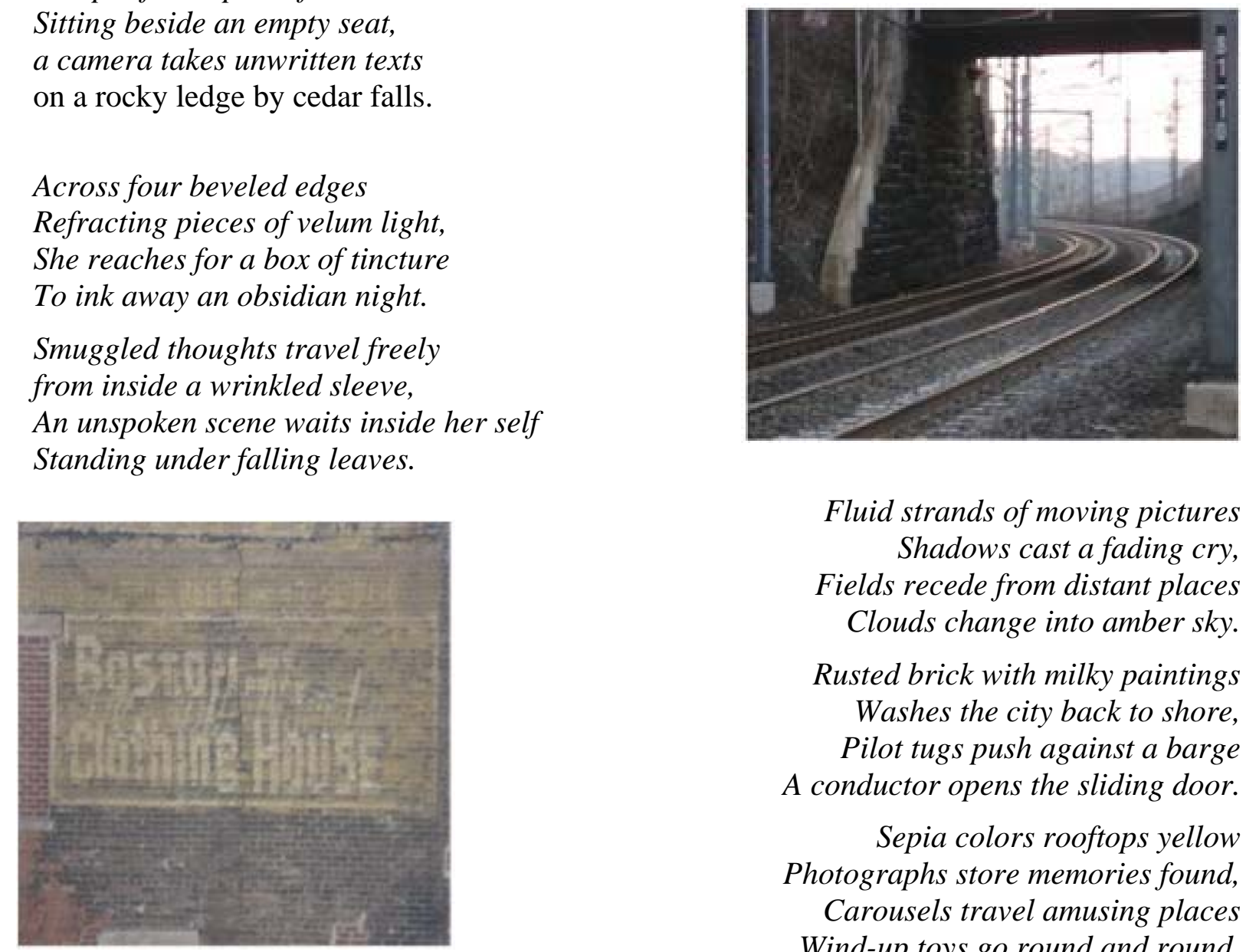

Fluid strands of moving pictures

Shadows cast a fading cry,

Fields recede from distant places Clouds change into amber sky.

Rusted brick with milky paintings

Washes the city back to shore,

Pilot tugs push against a barge A conductor opens the sliding door.

Sepia colors rooftops yellow Photographs store memories found, Carousels travel amusing places Wind-up toys go round and round.

Milkweed surrounds a railway crossing

Buses stop behind a barn, 
A lantern blinks a signal softly

Winds blow kites holding woolen yarn.

Weathered shutters close together

Driftwood shifts on rocky sand,

Sedges grow among the seashells

Grasses ground a concert band.

Whirligigs turn by backyard fences

Chimneys tilt against the rain,

Children play in tree top places

A rock just cracked a mullioned pane.

A cadence of a morning shower

The evening of a crimson tide, Waves break into wading basins

Marshes surround the eastern side.

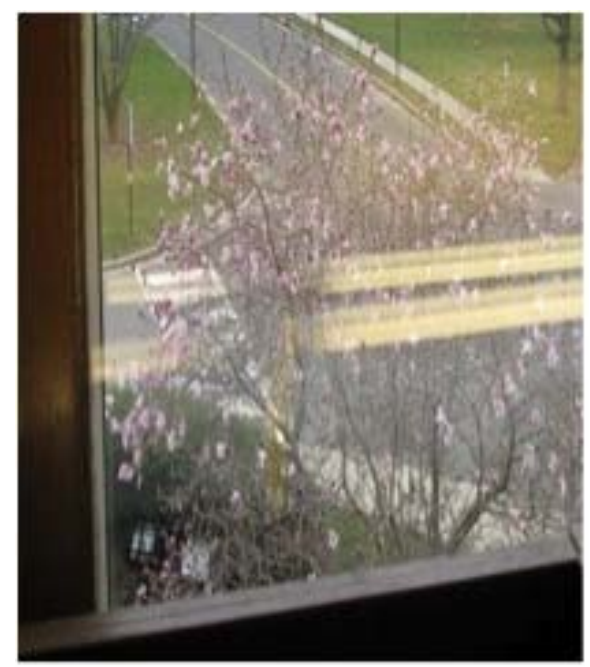

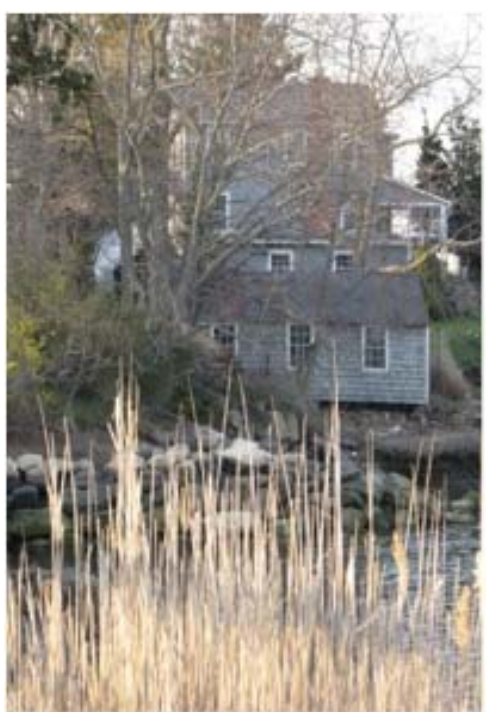

Ghostwriters draw their notes on canvas Boathouses list toward groves of pine, Cardinals call with one last message A memory is more than marking time.

Leaning into an aisle window A mandolin plays with a cello's bow, Rhythms, lyrics, sounds and meanings Recollections teach her ways to know.

Fountain pens coat parchment paper A blotter soaks spills of ginger tea, She landscapes sights in selected instants Her muse plays a harp in the key of $C$.

Quiet anticipation fidgets the nearby handles of relabeled bags.

The pull of luggage packs crowds into temporary quarters.

Entering the underground gates,

A display board resets planned arrivals

Departing from former times on future dates.

Upstairs the clock tower watches converging views with a single lens.

High backed wooden benches provide space for silent thought.

Lingering by a field of flowering thyme,

A train's whistle summons nearby stanzas

Recollected verse composed in syncopated rhyme.

(C. Morawski, personal communication, undated) 


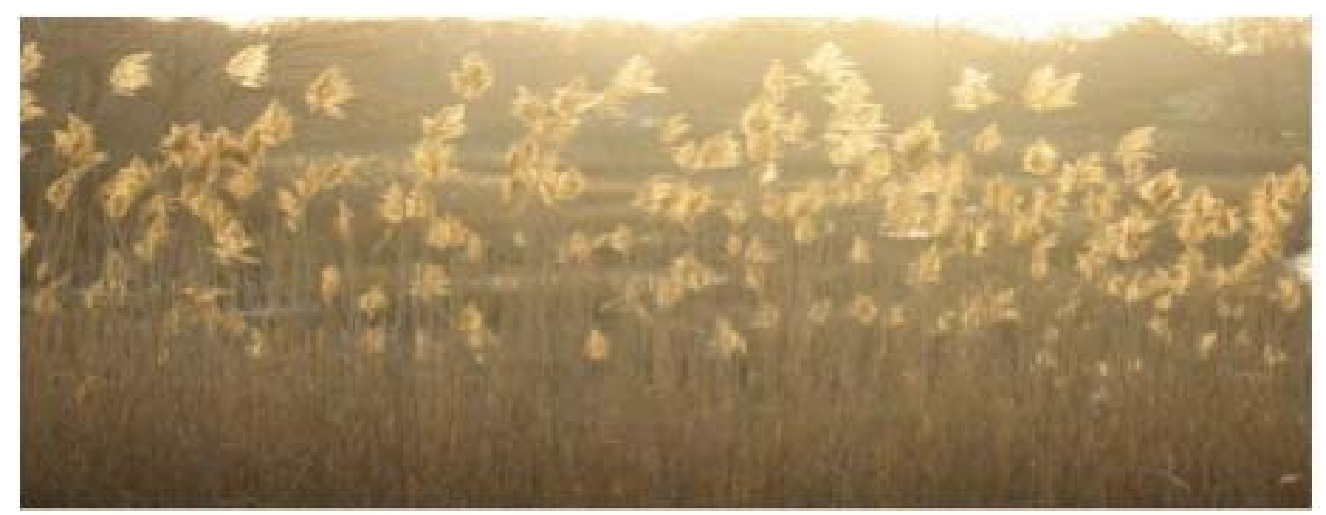

After placing the stereoscope on the table again, I catalogue my viewing cards in the now of then. A morning rain. The crimson tide. Waves breaking into basins by a listing side. Connelly and Huber (2002) underscore the importance of reflecting on our own lived experiences to make meaning in our lives as teachers. In the previous pages, I traveled past routes into the presence of recurring stops - apertures into the meaning of my everyday classroom practice. Filtered through the lenses of my stereoscopic viewer, both word and image provoke traces of teaching narrated by remembered sights set in recurring time. When I invite my students to sketch a cello's tune, I recall grasses grounding a concert at noon. While creating a lesson on ways to write, I see refracting pieces of velum light. To introduce a stanza on falling leaves, I reach for words smuggled in a wrinkled sleeve. O’Reilly-Scanlon (2002) talks about recollections as openings or clues into our ways of teaching via "what was once there and what is there for us now" (p. 77). Glimpsed in the transience of everyday scenes, the material of memory reconsiders my teaching with me. Milkweed. Shutters. A lantern's wink. I place paints and brushes by the classroom sink...

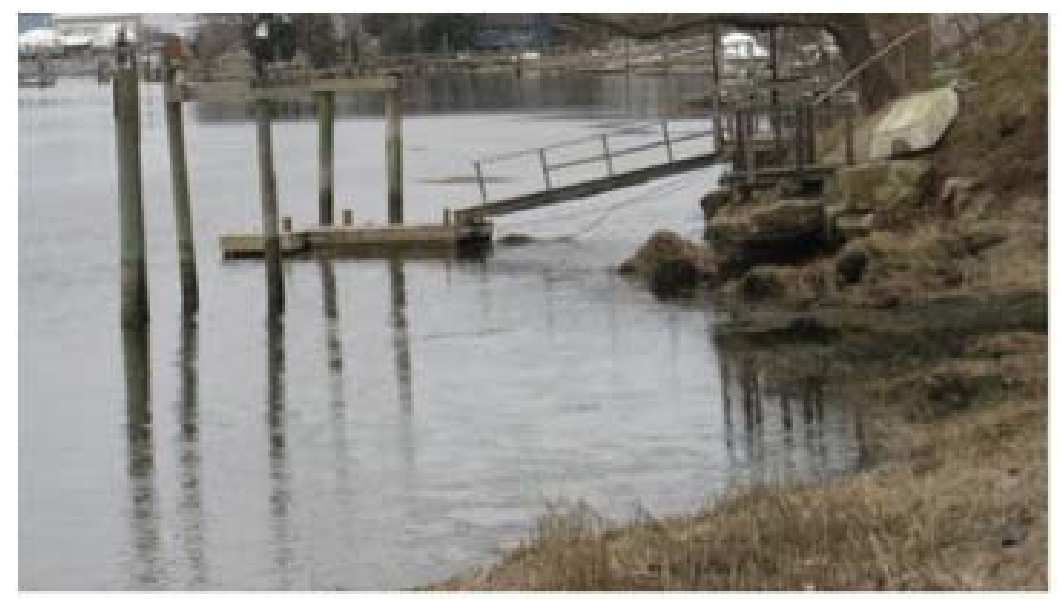

\section{Epilogue}

In his seminal book on teachers' inquiry into the meaning of what they are and what they teach, Jersild (1955) states, "When teachers face themselves, they face a hard struggle, but they also look forward to great rewards" (p. 125). Although the continuing examination of my own early memories provokes a range of both reassuring and troubling responses, the process always fills in another clue, another piece of what I am and what I teach in relation to my classroom work in pre-service language/arts. It is not just the contents of the specific events that provide the working material for my narrative. It is also the range of ways in which these moments move 
from the mind and body to the page: Sometimes with structure and explanation (Morawski, 2008 Morawski \& Palulis, 2009), while at other times with the simplicity of performance (Morawski, 2009, 2010); each time that I enter a memory, the ensuing changes in my narrative shifts to enlighten and revise my teaching practice in the present. Just as Cisneros (2007) said about what she would do at the end of her writing on Mango Street, I will now go away to come back, back where memories loom and hide, waiting to enter and once again revise my recurring narrative of teaching. 


\section{References}

Adler, A. (1958). The practice and theory of individual psychology. Patterson, NJ: Littlefield, Adams.

Butler-Kisber, L. (2010). Qualitative inquiry: Thematic, narrative and arts-informed perspectives. Los Angeles, CA: Sage.

Cisneros, S. (2007). The house on Mango Street. New York, NY: Vintage Contemporaries.

Clandinin, D., \& Huber, J. (2002). Narrative inquiry: Toward understanding life’s artistry. Curriculum Inquiry, 32, 161-169.

Connelly, F., \& Clandinin, F. (2006). Narrative inquiry. In J. Green, G. Camili, \& P. Elmore (Eds.), Handbook of complementary methods in education research (3rd ed.), (pp. 477-487). Mahwah, NJ: Lawrence Erlbaum.

Dillard, A. (1982). Teaching a stone to talk. New York, NY: Harper Perennial.

Hestor, R. (2004). Early memory and narrative. Journal of Individual Psychology, 60, 338-347.

Jersild, (1955). When teachers face themselves. New York, NY: Teachers College Press.

Leggo, C. (2007). Tangled lines: The art of researching our lives. Journal of Educational Thought, 41, 191-199.

Morawski, C. (2008). Watercolors awash in crayoned responses: Teaching narrative in artsbased praxis. Language and Literacy, 10, 1-28.

Morawski, C. (2009). From within a teaching narrative: Poetics past into presents of recurrent time. Educational Insights, 13, 1-4.

Morawski, C. (2010). Remnants along a flagstone path. English Quarterly, 40, 106-107.

Morawski, C., \& Palulis, P. (2009). Auto/ethnographies as teaching lives: An aesthetics of difference. Journal of Curriculum Theorizing, 25, 6-24.

O’Reilly-Scanlon, K. (2002). Muted echoes and lavender shadows: Memory work and selfstudy. In C. Kosnik, A. Freese, \& A. Samaras (Eds.), Making a difference in teacher education through self-study.(2) Proceeding of the Fourth International Conference of the Self-Study of Teacher Education Practices, Herstmonceux Castle East Sussex, England (pp. 74-78) Toronto, Ontario: OISE, University of Toronto.

Schneider, M. \& Stone, M. (1998). Narrative: Creating stories. Journal of Individual Psychology. 54, 413-415.

Seuss, D. (1947). McElligot's pool. New York, NY: Randon House. 